\title{
Development of New Biokinetic-Dosimetric Models for the Simulation of lodine Blockade in the Case of Radioiodine Exposure in Man
}

\section{(이요 $\Theta$}

\author{
Authors \\ Alexis Rump ${ }^{1}$, Stefan Eder ${ }^{1}$, Andreas Lamkowski ${ }^{1}$, Manabu Kinoshita², Tetsuo Yamamoto ${ }^{3}$, Michael Abend', \\ Nariyoshi Shinomiya ${ }^{2}$, Matthias Port ${ }^{1}$
}

\author{
Affiliations \\ 1 Bundeswehr Institute of Radiobiology, Munich, Germany \\ 2 Japan Self Defense Forces, National Defense Medical \\ College Research Institute, Tokorozawa, Japan \\ 3 Japan Ground Self Defense Forces, Military Medicine \\ Research Unit and Ministry of Defense Clinic, Tokyo, Japan
}

Key words

Medical NRBC-protection, nuclear and radiological emergency, radioiodine, iodine blockade

received $\quad 13.02 .2019$

accepted $\quad 06.06 .2019$

\section{Bibliography}

DOI https://doi.org/10.1055/a-0960-5590

Published online: 7.8.2019

Drug Res 2019; 69: 583-597

(c) Georg Thieme Verlag KG Stuttgart · New York

ISSN 2194-9379

Correspondence

Alexis Rump, MD, PhD, MHBA

Bundeswehr Institute of Radiobiology

Neuherberg Str. 11

80937 Munich

Germany

Tel.: + 49/89/2296 2282, Fax: + 49/89/2296 2255

alexisrump@bundeswehr.org

\section{ABSTRACT}

In the case of nuclear incidents, radioiodine may be liberated. After incorporation it accumulates in the thyroid and by internal irradiation enhances the risk of cancer occurrence. By administering a large dose of non-radioactive iodine the uptake of radioiodine into the gland can be inhibited ("iodine blockade"). Biokinetic models using first order kinetics are not suited to simulate iodine blockade, as the uptake into the gland is mediated by a saturable active transport. Therefore, we integrated an uptake mechanism described by a Michaelis-Menten kinetic into a simple ICRP biokinetic model. We moreover added a total uptake blocking mechanism representing the Wolff-Chaikoff effect becoming active when the gland is saturated with iodine. The validity of the model was ascertained by comparison with IMBA software. The competition of radioiodine and stable iodine at the membrane carrier site was modeled according to the rate law for monomolecular reactions for competing substrates. Our simulations show that competition for the uptake at the membrane carrier site accounts for about $60 \%$ and the saturation of the gland with iodine for over $35 \%$ of the total protective efficacy that exceeds $95 \%$. Following acute radioiodine exposure, it is preferable to administer a single large dose of stable iodine. In the case of continuous radioiodine exposure, a single dose of stable iodine is less effective than after an acute exposure and splitting the total available dose and shortening the dosage intervals enhance efficacy. Model-based simulations may be a useful tool to develop antidote dosage schemes for uncommon emergencies.

\section{Introduction}

Large amounts of radioactive materials may be liberated in the case of nuclear weapon detonations or accidents in industrial nuclear facilities. The released radionuclides include fission products, activation products, uranium, plutonium and transuranic elements [1]. After a nuclear weapon detonation more than 300 nuclides from 36 elements have been identified and the composition will change over time with the decay of short lived nuclides [2]. Moreover, the dispersion of the radioactive material may show substantial differ- ences. In the case of an "air burst" of a nuclear weapon, if the fire ball does not reach the earths' surface, small particles will be formed, reaching higher atmospheric levels and leading to regional and global fallout, but relatively little early local fallout [2, 3]. On the contrary, in the case of a detonation near the earths' surface, the radioactive cloud will be heavily loaded with ground debris (vaporized or melted material drawn up into the cloud) adsorbing radionuclides and leading to early local fallout being highly radioactive (e. g., Castle Bravo nuclear testing incident in 1954)[2-5]. Sim- 
ilarly, the isotopic composition of the liberated radioactive material may greatly differ in the case of accidents in nuclear facilities and the resulting fallout will depend on the distance from the source $[1,6]$. After the Chernobyl power plant accident, the volatile radioiodine and cesium radionuclides reached higher atmospheric levels and were transported over larger distances than strontium and particularly fuel particles that deposited in the near zone around the plant [1]. In addition, the meteorological conditions are of major importance for the dispersion. Besides wind direction and intensity, precipitations are an important determinant for dispersion, as radioactive particles of any size will be incorporated or attached to falling raindrops and thus come down to earth [7].

Among the fission products formed by a nuclear weapon detonation or in a nuclear power reactor, radioiodine is one nuclide of particular concern. Uranium-235 usually splits asymmetrically and radioiodine (I-131) falls in one of the favored mass number regions of the fission products (bimodal distribution with peaks between $90-100$ and $130-140$ ). The fission yield of iodine- 131 is relatively high with about $3 \%$ (the yield is the number of a particular radionuclide produced for every 100 fission events). And moreover, iodine has a high volatility, so that it is readily spread [8].

In fallout radioiodine exists in three different physical forms: gaseous inorganic, gaseous organic and adsorbed to particles [7]. The partitioning between these forms may change over time after its liberation from the source. After inhalation, iodine (and as it is chemically identical radioiodine) is rapidly absorbed into the blood. Molecular iodine vapor $\left(\mathrm{I}_{2}\right)$ is mostly retained in the conducting airway and transferred to the gastrointestinal tract where it is absorbed [9-11]. Gaseous organic compounds (methyliodide) are very rapidly absorbed through the lungs at about $70 \%[9,10]$. The deposition of iodine adsorbed on particles depends on the diameter of the particulates, but in case it is not absorbed through the airway it is transferred for absorption to the gastrointestinal tract. Thus, for practical purposes radioiodine absorption can be considered to be complete [9-11].

After absorption into the body, inorganic iodine distributes in the extracellular space. Inorganic iodine is mainly eliminated through the kidney with a clearance between 30 and $50 \mathrm{ml} / \mathrm{min}$ [9]. lodine is transported into the thyroid gland by an active carrier mechanism (iodide-sodium-symporter) through the basolateral membrane of the follicular cells and the uptake fraction into the gland amounts from $10-40 \%$ of the intake into the body $[9,10,12]$. The uptake into the thyroid is quite rapid and within 3-6.5 h about half of the total uptake fraction has entered the gland $[9,10,12]$. However, plasma clearance into the thyroid (normally $16-18 \mathrm{ml} / \mathrm{min}$ ) shows a large variability and depends on the iodine concentration, the regular iodine supply (e.g., iodine deficiency) and thyroid function $[9,13]$. After radioiodine uptake, the radionuclide will concentrate in the thyroid and cause an internal irradiation of the gland. This may be a therapeutic objective when treating thyroid tumors with radioiodine. However, after a nuclear event with radioiodine release, it is an unwanted incident as the radiological dose that is absorbed by the gland will enhance the probability of stochastic health effects in the long run (e. g., occurrence of cancer).

After the Castle Bravo nuclear testing incident on the Bikini atoll (1954) with an explosive yield much higher than calculated and moreover unexpected meteorological conditions, the inhabitants of the Rongelap Island community were reported to have absorbed an internal equivalent dose to the thyroid of 7.6 Gy on the average [5]. For the thyroid the internal dose was much higher than the dose absorbed by external irradiation (1.6Gy) [5]. Following the nuclear plant accident in Chernobyl the estimated thyroid doses were lower, but showed large variations (among 600 recovery operation workers: average $0.21 \mathrm{~Gy}$, but up to $3 \mathrm{~Gy}$ in individual cases; children in Pripyat and others in the $30 \mathrm{~km}$ zone (Ukraine): 0.1-2.1 Gy) [14].

$A$ reduction of radioiodine uptake into the thyroid can be achieved by administering a large dose of stable (not radioactive) iodine shortly before or shortly after radioiodine exposure ("iodine blockade") $[9,10,15,16]$. Although the scientific evidence of effectiveness is considered as very low, due to sparse clinical data, "provision of iodine thyroid blocking (ITB) to people who are at risk of being exposed to radioiodine should be implemented as an urgent protective action, within the frame of a justified and optimized protection strategy" according to the World Health Organization [16]. It is considered that if properly administered the potential of an iodine blockade to cause harm is low [16]. Recommendations to perform an iodine blockade in the case of radioiodine exposure is also part of national guidelines for nuclear or radiological emergencies in many countries (e. g., Germany, France) $[17,18]$.

Several mechanisms may be involved in the protection of the gland: 1 . Competition between radioiodine and stable iodine at the membrane carrier site of the thyroid cells and 2 . A rapid inhibition of hormonal synthesis, i. e., an inhibition of the inclusion of (radio) iodine into the hormone precursor thyroglobuline (Wolff-Chaikoff effect) $[9,10,19]$. Although the mechanism of the latter is not fully understood, it seems that it is at least in part mediated by the inhibition of peroxidase activity in the follicular cells [20]. However, the Wolff-Chaikoff effect is fading after $24-48 \mathrm{~h}[9,10,20]$ and therefore may become ineffective in the case of prolonged radioiodine exposure.

There is a consensus that an iodine blockade must be administered shortly before or at least within several hours after radioiodine exposure to be efficacious [16-18]. This is easy to understand if considering the rapid uptake of radioiodine from the blood into the gland. A single administration of $100 \mathrm{mg}$ iodine (e. g., $130 \mathrm{mg}$ potassium iodide) in adults is usually considered as sufficient [16-18]. In the case of prolonged or repeated radioiodine exposures, it is however acknowledged that it might be necessary to give an additional dose of stable iodine to ensure thyroid protection $[9,10,16,18]$. The Fukushima disaster again raised the issue how to protect people from repeated releases of radioiodine. Up to now there are no clear rules when to use just a single stable iodine dose and when to administer repetitive doses at what dosages. In a radiological or nuclear emergency, there will however be no time to study the specific case in all details, as a rapid initiation of treatment is crucial for efficacy. It must also be acknowledged that the topic is uncommon to most physicians. Therefore there is a need for a clear and concrete guidance how to act toward patients that may be coming in large numbers at hospitals or clinics to seek advice and/or get treatment. That's why to get more insights in this issue, we tried to develop a biokinetic-dosimetric model that permits to simulate different radioiodine exposure scenarios with different iodine blockade schemes. This tool may be used to get a better understanding of the therapeutic implications of the kinetic mechanisms involved 
and may permit to draw quantitative conclusions on timelines and dosages for emergency planning.

\section{Method}

\section{Model development}

\section{Integration of an active carrier uptake mechanism into the ICRP model (Model 1)}

We departed from a biokinetic model for iodine intended for a reference adult introduced by Riggs [21] and widely used in radiation protection by the International Commission for Radioprotection (ICRP) [22, 23]. As we are interested in the competition of radioiodine and stable iodine, we did not consider the kinetics of iodine integrated in thyroid hormones being secreted from the thyroid and their elimination. Therefore, the corresponding compartments were deleted, giving rise to a simple two compartment model. The central compartment represents the extracellular space including red blood cells with an estimated approximate volume of distribution of $16 \mathrm{I}$ (water: $60 \%$ of body weight; extracellular space $1 / 3$, i.e., 14 I and red blood cells about $2 \mathrm{I}$ ). lodine is eliminated from the central compartment by renal excretion that is a first order process that is not saturable (rate constant: $1.9404 \mathrm{~d}^{-1}$ ). In the case of radioiodine only, an additional elimination out of the central compartment occurs by physical decay (decay constant: $0.086625 \mathrm{~d}^{-1}$ ). In addition, radioiodine as well as stable iodine are transported into the peripheral compartment representing the thyroid and acting as a sink.

In the ICRP model iodine transport into the thyroid is modelled as a first order process (rate constant: $0.8316 \mathrm{~d}^{-1}$ ). However, iodine transport into the thyroid occurs through an active carrier (Na-I-Symporter, NIS) and not only by passive diffusion. This transfer process can be described in analogy to an enzyme reaction by Michaelis-Menten kinetics:

$\mathrm{T}=\frac{\mathrm{T}_{\max } * \mathrm{C}}{\mathrm{K}_{\mathrm{m}}+\mathrm{C}}$

T is the transport capacity through the membrane at the time when $\mathrm{C}$ is the concentration of iodine in the extracellular space. The Michaelis-Menten constant $\left(\mathrm{K}_{\mathrm{m}}\right)$ and the maximum transport capacity $\left(T_{\max }\right)$ are the parameters of the equation.

For iodine concentrations far below $\mathrm{K}_{\mathrm{m}}$ (i. e., $\mathrm{K}_{\mathrm{m}}+\mathrm{C} \sim \mathrm{K}_{\mathrm{m}}$ ), it is justified to approximate the influx by a first order process (first order process rate constant $\left.=T_{\max } / K_{m}\right)$, but this is not legitimate for iodine dosages leading to concentrations approaching or exceeding $\mathrm{K}_{\mathrm{m}}$. Therefore, for our purpose we modelled the transport process using Michaelis-Menten kinetics. For human NIS, a $\mathrm{K}_{\mathrm{m}}$ of $9 \mu \mathrm{mol} / \mathrm{I}$ has been reported and this value was used in our model [24]. $T_{\max }$ was derived from the $\mathrm{K}_{\mathrm{m}}$ and the constant rate of the ICRP model applicable when the transport process approaches a first order kinetic $\left(k=0.8316 d^{-1}\right): T_{\max }=K_{m}{ }^{*} k=9 * 0.8316=7.48 \mu \mathrm{moll}^{-1} \mathrm{~d}^{-1}$.

\section{Modelling of a competitive thyroid uptake of radioactive and stable iodine}

We applied the rate law for monomolecular irreversible enzyme reactions with any number $i$ of competing substrates applied to the carrier mediated transport process $[25,26]$ :
$\mathrm{T}_{1}=\frac{\mathrm{T}_{\max } * \mathrm{C}_{1}}{\mathrm{~K}_{\mathrm{m} 1} *\left(1+\sum_{i=2}^{n} \frac{\mathrm{C}_{\mathrm{i}}}{\mathrm{K}_{\mathrm{mi}}}\right)+\mathrm{C}_{1}}$

with $T_{i}$ the transport rate for substrate $i, C_{i}$ the concentration of substrate $i, K_{m i}$ the Michaelis-Menten constant for substrate $i$ and $\mathrm{T}_{\max }$ the maximum transport rate. In our model, we have only 2 competing entities that are chemically identical (radioiodine and stable iodine), so that they share the same Michaelis-Menten con$\operatorname{stant}\left(K_{\mathrm{m}}=9 \mu \mathrm{mol} / \mathrm{I}\right)$.

As we used iodine amounts $\mathrm{m}$ (in $\mu \mathrm{mol}$ ) and not concentrations in our model, we multiplied the numerator and denominator of the equation with the volume of the extracellular space assumed to be 16I. Moreover, when computing $\mathrm{T}_{\max }$ from $\mathrm{K}_{\mathrm{m}}$ and $\mathrm{k}$ the value was also multiplied by the distribution volume of $16 \mathrm{l}$. Thus, the equations finally used to describe the uptake of radioiodine and stable iodine into the thyroid using weight units were as follows:

For radioiodine $: \mathrm{T}(\mathrm{I}-131)=\frac{119.75 * \mathrm{~m}(\mathrm{I}-131)}{144+\mathrm{m}(\mathrm{I}-131)+\mathrm{m}(\mathrm{I})}$

For stable iodine $: \mathrm{T}(\mathrm{I})=\frac{119.75 * \mathrm{~m}(\mathrm{I})}{144+\mathrm{m}(\mathrm{I}-131)+\mathrm{m}(\mathrm{I})}$

The whole model integrating the disposition of radioiodine and stable iodine is shown in > Fig. 1. All computations were done using Berkeley Madonna Software.

\section{Adding a saturation mechanism into the ICRP model with integrated carrier uptake (Model 2 and 3)}

It has been reported that a further uptake of iodine is completely blocked when the gland is saturated $[21,27,28]$. This may reflect the Wollf-Chaikoff effect. We integrated this blocking mechanism in model 1. It was reported that this total uptake block becomes effective when the iodine content of the gland increases by $0.35 \mathrm{mg}$ $(2.7581 \mu \mathrm{mol})[21,27,28]$. We used this value in model 2 .

In model 3 we used the protective efficacy determined experimentally in volunteers by Blum et al. [29] (for $100 \mathrm{mg}$ stable potassium iodide: $98 \% \pm 3 \%$ ). Assuming protection by the competition at the carrier site with the parameters of model 1 , we calculated the additional iodine uptake causing saturation of the gland as to get a total protection rate corresponding to the empirical data. A total iodine uptake block is thus expected when the iodine amount that has entered the gland reaches $0.448 \mathrm{mg}$ (instead of $0.35 \mathrm{mg}$ in model 2).

\section{Calculation of the thyroid equivalent dose from the radioiodine uptake into the gland}

A simple calculation of the (committed effective) dose by multiplication of the radioiodine intake with the dose coefficient for inhalation or ingestion of radioiodine is not possible in our case, as it supposes a defined and constant uptake fraction into the thyroid. Therefore, we used the Marinelli/Quimby method [30] for the contribution of the $ß$-radiation and the geometrical factor method of Hine et al. [31] for the (low) contribution of the $y$ radiation to the thyroid equivalent dose. The method has also been described for thyroid equivalent dose computations in the more recent literature 


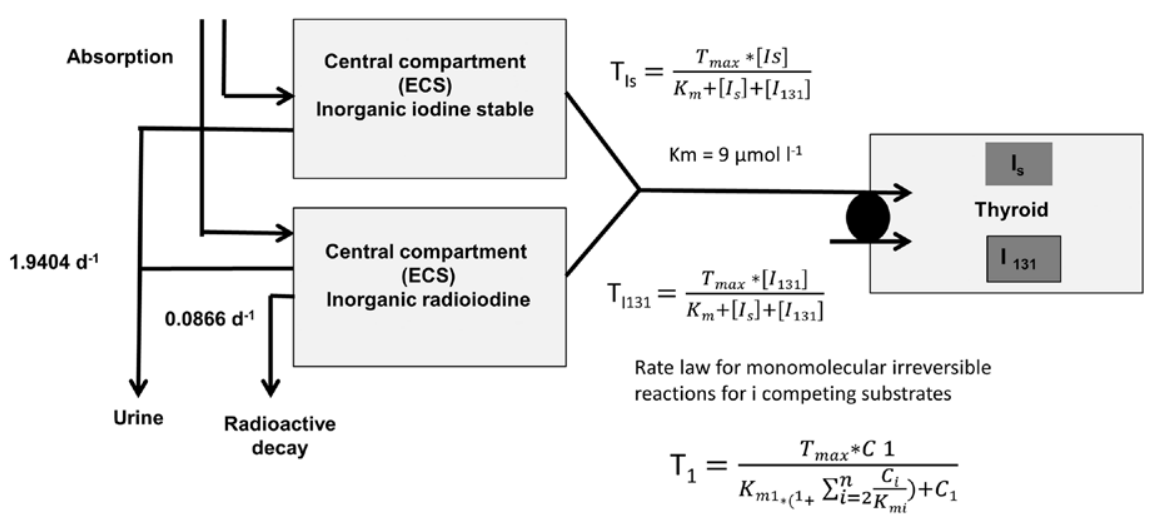

- Fig. 1 Model 1 (Basic model). Compartment model derived from a simple ICRP biokinetic model with an integrated carrier uptake mechanism described by a Michaelis-Menten kinetic. Competition of stable iodine and radioiodine is modeled by applying the rate law for monomolecular irreversible enzyme reactions to the transport mechanism. Model 2 and 3 are derived from model 1 by adding a gland saturation threshold leading to a total uptake block.

$[7,32,33]$. As radioiodine mostly concentrates in the gland, for radiation emitted from other source organs to the thyroid as a target, the specific absorbed fractions were set to 0 . Thus, the following equation was used:

$\mathrm{D}=\mathrm{C}_{\text {max }} * \mathrm{~T}_{\text {eff }} *\left(73.8 * \overline{\mathrm{E}}_{\beta}+0.0346 * \mathrm{~T} * \overline{\mathrm{g}}\right)$

With $D$ the total dose from $B$ and $y$ radiation (rad), $C_{\max }$ the maximum concentration of the radionuclide in tissue $\left(\mu \mathrm{Ci} \mathrm{g}^{-1}\right), T_{\text {eff }}$ the effective half-life in the tissue (days) (7.3 days for I-131 in adults), $\overline{\mathrm{E}}_{\beta}$ the average beta energy (MeV per disintegration) (0.18 MeV for I-131), $T$ the specific $y$ ray constant ( $R$ per $\mathrm{mCi} \mathrm{h}^{-1}$ at $\left.1 \mathrm{~cm}\right)\left(2.2 \mathrm{RmCi}^{-1} \mathrm{~h}^{-1}\right)$ and $\bar{g}$ the average geometrical factor for the tissue or organ, equal to $3 \pi \mathrm{r}$ for spheres with radii $<10 \mathrm{~cm})(r=1.27 \mathrm{~cm}$ in adults assuming that the thyroid is made of two identical spheres of unit density) (values from [7]). As we used radioiodine amounts and not concentrations in our model, we replaced the maximum concentration $C_{\max }$ by the maximum accumulated amount divided by the thyroid weight assumed to be on the average $17 \mathrm{~g}$ in an adult [7]. After transformation taking into account the units used in the original equation, we applied the following formula to calculate the thyroid equivalent dose:

$\mathrm{D}(\mathrm{mSv})=1.647 * 10^{-3} *$ accumulated $\mathrm{I}-131$ in the thyroid $(\mathrm{Bq})$

It should be emphasized that the equation is used to calculate the thyroid equivalent dose (energy dose * quality factor of the radiation, for $ß$ and $\gamma$ radiation the quality factor $=1$ ), and not an effective dose additionally taking into account the radiation sensitivity of a tissue regarding stochastic health effects (effective dose = equivalent dose * sensitivity factor, for the thyroid the sensitivity factor $=0.05$, but equivalent and effective doses are both expressed with the same unit Sv).

\section{Application of the new models}

\section{Validation of model 1 by comparison with doses computed with IMBA software}

Equivalent doses calculated with our biokinetic model 1 and the described dosimetric model were compared to values obtained with the Integrated Modules for Bioassay Analysis (IMBA) software [34]. IMBA is a commercial software based on the biokinetic models and dose coefficients of the ICRP to calculate the committed effective doses after incorporation of numerous radionuclides. However, it also displays the equivalent doses absorbed by the different organs and tissues.

The equivalent thyroid doses for radioiodine intakes ranging from $100 \mathrm{~Bq}$ to $10^{15} \mathrm{~Bq}$ were calculated. Although refined models have been proposed for ingestion or the inhalational pathways of iodine $[35,36]$, to exclude effects related to the structure and parameters of the inhalational or gastrointestinal model, (radio)iodine was administered by injection directly into the central compartment. We consider that this is legitimate as the absorption rate for iodine is rapid and the absorption extent almost complete.

Using the specific activity of iodine-131 $\left(4.6^{*} 10^{15} \mathrm{~Bq} / \mathrm{g}\right)$ and its atomic weight, we computed for the different radioactivity intakes the corresponding molar value to be entered in model 1. We applied our model and determined for the different radioiodine intakes the total molar amount of radioiodine that has entered the thyroid, and after converting the molar values back into activity, we used the radiobiological equation described in the previous section to calculate the thyroid equivalent dose.

\section{Estimation of the efficacy of a single dose of $100 \mathrm{mg}$ stable iodine}

For the different radioiodine intakes considered in the previous section, we repeated the simulations with the additional administration of stable iodine: $100 \mathrm{mg}$ once, at the same time as acute radioiodine injection. The thyroid dose was again determined as described in the preceding paragraph. The efficacy of the iodine 
blockade was determined as the complementary value of the dose reduction factor:

Efficacy $=1$ - (thyroid dose with iodine blockade / thyroid dose without iodine blockade)

Moreover, the absorption fraction was computed as the quotient of the total activity uptake into the gland and the total initial activity intake into the model (initial activity in the central compartment for simulations by injection).

\section{Estimation of the protective efficacy of different single doses of stable iodine}

We repeated our simulations by adding to the radioiodine $(700000 \mathrm{~Bq}$, leading based on IMBA calculations to the thyroid dose limit of $300 \mathrm{mSv}$ according to German regulations) different doses of stable iodine in a range of $5 \mathrm{mg}$ to $1000 \mathrm{mg}$, administered at the same time as the radioiodine as single doses into the central compartment. The dose-effect-relation was examined by fitting the data to a sigmoidal Hill equation with 3 parameters $\left(E=a^{*} D^{b} / D 50^{b}+D^{b}\right)$ and the median effective dose was determined for the 3 models.

In a further step, we examined the efficacy of the different doses of stable iodine for a very low and a high radioiodine intake ( $100 \mathrm{~Bq}$ or $5^{*} 10^{6} \mathrm{~Bq}$ ) and also determined the median effective doses.

\section{Estimation of the protective efficacy of a single stable iodine dose depending on the time of blockade initiation}

In a further simulation, we determined the efficacy of iodine blockade with a single dose of $100 \mathrm{mg}$ stable iodine administered at different time points before or after acute radioiodine exposure. For model 1 we considered a time frame from $48 \mathrm{~h}$ before to $48 \mathrm{~h}$ after acute radioiodine exposure assumed to occur at $\mathrm{t}=0 \mathrm{~h}$. As the Wolff-Chaikoff effect is a reversible temporary phenomenon, it did not seem meaningful to simulate stable iodine administrations before radioiodine exposure using model 2 or 3 and that's why we considered only the period up to $48 \mathrm{~h}$ after exposure.

\section{Estimation of the protective efficacy of repetitive doses of stable iodine after acute radioiodine exposure using model 1}

As a conservative approach, simulations were performed using model 1 , as the Wolff-Chaikoff effect included in the models 2 and 3 is known to be fading after $24-48 \mathrm{~h}$. Calculations were performed for an acute intake of $700000 \mathrm{~Bq}$ radioiodine into the central compartment. At first we examined the repetitive administration of $100 \mathrm{mg}$ stable iodine given daily up to the 3rd day. The first dose was administered simultaneously with the radioiodine intake. Simulations were repeated with a higher stable iodine dose of $200 \mathrm{mg}$ daily.

Next we examined if the efficacy can be improved by the administration of smaller doses of $50 \mathrm{mg}$ stable iodine given repeatedly at shorter dosage intervals of $12 \mathrm{~h}$. The first stable iodine dose was again administered at the same time as radioiodine intake.
Estimation of the protective efficacy of stable iodine in the case of continuous radioiodine exposure using model 1

Using IMBA software, we determined that a continuous intake of $230000 \mathrm{~Bq} / \mathrm{d}$ of iodine-131 led to an equivalent thyroid dose of about $300 \mathrm{mSv}$ after an exposure time of 3 days (by injection $302 \mathrm{mSv}$, by ingestion $296 \mathrm{mSv}$ ). We chose an exposure period of 3 days based on the Castle Bravo incident on the Marshall Islands (Bikini atoll) where victims were exposed to fall out for this period of time. We simulated a continuous invasion of $230000 \mathrm{~Bq} / \mathrm{d}$ into the central compartment of our model for 3 days and computed the therapeutic efficacy of an iodine blockade with different dosage schemes, including single or repetitive administrations of stable iodine. The first dose of stable iodine was given at the beginning of radioiodine exposure.

\section{Application of the model to the Castle Bravo nuclear testing incident: What if potassium iodide tablets had been available?}

A literature search was performed to determine the early fallout exposure conditions of the inhabitants of the most affected island of Rongelap after the $15 \mathrm{Mt}$ detonation of a thermonuclear weapon in the Bikini atoll on March 1, 1954. The evacuation of the Rongelap Island community began after 2 days on March $3[5,14]$. On the average, the external dose absorbed was estimated with 1600 mGy and the internal dose to the thyroid with $7600 \mathrm{mGy}(=7600 \mathrm{mSv}$ for $ß$ and $\gamma$ radiation) (90\% uncertainty range, $5 \%$ to $95 \%: 1500-$ 23000 mGy) [5]. We used our model 1 to determine to what extent the internal thyroid dose could have been reduced if potassium iodide tablets had been available to the inhabitants and administered as a single or as repetitive doses immediately after radioiodine exposure. We assumed that till evacuation was completed, the victims were continuously exposed to fallout with a constant radioiodine exposure for a total of 3 days.

\section{Application of the model to a victim of the Fukushima incident: What if potassium iodide tablets had been administered at different dosages?}

Radioactivity release lasted over several days after the reactor accidents of Chernobyl and Fukushima: About 10 days in Chernobyl (peak the first day April 26) and 20 days in Fukushima (peaks on March 15 and 23, low release between March 26 to 29 and again smaller release on March 30). Total radioactivity release was nevertheless much less in Fukushima than in Chernobyl: The daily peak releases amounted to over $2000 \mathrm{PBq} \mathrm{d}^{-1}$ (Chernobyl on April 26) vs. less than $30 \mathrm{PBq} \mathrm{d}^{-1}$ (Fukushima on March 15); the total release of radioiodine (I-131) is estimated with $1760 \mathrm{PBq}$ in Chernobyl vs. $120 \mathrm{PBq}$ in Fukushima [6].

A group of 45 evacuees or short-term visitors who had stayed in Fukushima from March 11 to 18, 2011 was examined in a whole body counter at Nagasaki University. The mean radioiodine activity measured was $574.7 \mathrm{~Bq}$ and the maximum activity amounted to $3940 \mathrm{~Bq}$ [37]. The administration of stable iodine had not been officially ordered. Using our model 1, we reconstructed the radioiodine exposure for the person with the highest measured activity assuming a continuous exposure with radioiodine for 7 days and a 
- Table 1 Thyroid equivalent doses (D) after the acute intake by injection of defined activities of radioiodine (I-131) calculated with IMBA software or our basic model 1 without or with an iodine blockade with $100 \mathrm{mg}$ stable iodine administered at the same time as the radioiodine exposure. The efficacy of the iodine blockade is calculated according to the formula Efficacy $=1$ - (dose with blockade / dose without blockade).

\begin{tabular}{|c|c|c|c|c|}
\hline $\begin{array}{l}\text { Intake } \\
\text { (Bq) }\end{array}$ & $\begin{array}{l}\text { Dose IMBA } \\
(\mathrm{mSv})\end{array}$ & $\begin{array}{l}\text { Dose model } 1 \text { without blockade } \\
\text { (mSv) }\end{array}$ & $\begin{array}{l}\text { Dose model } 1 \text { with blockade } \\
(\mathrm{mSv})\end{array}$ & Blockade efficacy \\
\hline 100 & 0.0437 & 0.0479 & 0.01922 & 0.599 \\
\hline $5 * 10^{3}$ & 2.19 & 2.396 & 0.961 & 0.599 \\
\hline $10^{4}$ & 4.37 & 4.792 & 1.923 & 0.599 \\
\hline $5 * 10^{4}$ & 21.9 & 23.961 & 9.614 & 0.599 \\
\hline $10^{5}$ & 43.7 & 47.9 & 19.2 & 0.599 \\
\hline $2.5^{*} 10^{5}$ & 109 & 119.8 & 48.1 & 0.599 \\
\hline $5 * 10^{5}$ & 219 & 239.6 & 96.1 & 0.599 \\
\hline $10^{6}$ & 437 & 479.2 & 192.3 & 0.599 \\
\hline $2 * 10^{6}$ & 875 & 958.5 & 384.6 & 0.599 \\
\hline $5 * 10^{6}$ & $2.19 * 10^{3}$ & $2.396 * 10^{3}$ & 961.4 & 0.599 \\
\hline $5 * 10^{7}$ & $2.19 * 10^{4}$ & $2.396 * 10^{4}$ & 9614 & 0.599 \\
\hline $10^{12}$ & $4.37^{*} 10^{8}$ & $4.772 * 10^{8}$ & $1.921 * 10^{8}$ & 0.598 \\
\hline $10^{13}$ & $4.37^{*} 10^{9}$ & $4.601^{*} 10^{9}$ & $1.902 * 10^{9}$ & 0.587 \\
\hline $5 * 10^{13}$ & $2.19^{*} 10^{10}$ & $1.999 * 10^{10}$ & $9.131 * 10^{9}$ & 0.543 \\
\hline $10^{14}$ & $4.13^{*} 10^{10}$ & $3.475 * 10^{10}$ & $1.740 * 10^{10}$ & 0.499 \\
\hline $2 * 10^{14}$ & $8.75^{*} 10^{10}$ & $5.616 * 10^{10}$ & $3.190 * 10^{10}$ & 0.432 \\
\hline $4.6 * 10^{14}$ & $2.01 * 10^{11}$ & $7.754 * 10^{10}$ & $4.811 * 10^{10}$ & 0.380 \\
\hline $7.5^{*} 10^{14}$ & $3.28 * 10^{11}$ & $1.131 * 10^{11}$ & $8.409 * 10^{10}$ & 0.257 \\
\hline $10^{15}$ & $4.37^{*} 10^{11}$ & $1.275^{*} 10^{11}$ & $9.967 * 10^{10}$ & 0.218 \\
\hline
\end{tabular}

whole body counting 1 week later, i. e., 7 days after termination of exposure. Furthermore, we simulated the effects that different dosage shemes of stable iodine would have had on the thyroid equivalent dose.

\section{Results}

\section{Validation of model 1 (basic model) by comparison with doses calculated with IMBA software}

Without iodine blockade the thyroid equivalent doses calculated using IMBA or our model 1 are shown in > Table 1 The doses calculated with IMBA software or using our model 1 are in the same order of magnitude for activity intakes up to $10^{12} \mathrm{~Bq}$, with the values calculated with our model exceeding the values determined with IMBA by about $10 \%$ ( $\triangleright$ Table 1 ). At activity intakes higher than $10^{12} \mathrm{~Bq}$ the doses computed with our model starts to become lower than the IMBA values and the higher the intake activity the higher the difference. At $10^{15} \mathrm{~Bq}$ the equivalent dose computed with our model amounts to only $29.2 \%$ of the dose calculated with IMBA. This reflects a saturation mechanism becoming effective in our model, whereas IMBA continues to apply a first order kinetic independently of the activity of the intake.

\section{Estimation of the protective efficacy of a single dose of $100 \mathrm{mg}$ stable iodine}

For a usual recommended single dose of $100 \mathrm{mg}$ stable iodine administered into the central compartment at the same time as radioiodine (I-131), the blockade calculated using our model 1 could achieve a reduction of the thyroid equivalent dose for the period up to 10 days from exposure of $59.9 \%$ in the activity range examined up to very high radioiodine activities about $10^{12} \mathrm{~Bq}$ ( $\triangleright$ Table 1 ). Increasing further the activity administered is associated with a decrease in protective efficacy.

By the iodine blockade the uptake fraction for radioiodine was reduced from 29.1 to $11.7 \%$ (period up to 10 days) and amounted to $12.3 \%$ for stable iodine up to a radioiodine intake of about $10^{12} \mathrm{~Bq}$. Further increasing radioactivity intake was associated with a lower uptake fraction into the gland even without iodine-blockade, but the difference between the uptake fractions with and without blockade diminished, reflecting the lower protective efficacy (at $10^{15} \mathrm{~Bq}$, uptake without blockade: $7.74 \%$, with blockade: $6.05 \%)$.

For the first day, the protective efficacy is slightly higher than for the 10 days period ( 0.661 vs. 0.599 ; uptake fraction is reduced from 29.1 to $11.7 \%$ after 10 days, but from 27.4 to $9.3 \%$ after 1 day) (• Table 2 ). This can be easily explained by the time course of the uptake into the gland. The amount of radioiodine accumulating in the thyroid rapidly increases during the first day after the acute intake and seems to reach a plateau after two days ( $>$ Fig. 2). This is less than the 4 to 5 half-times calculated from the uptake rate constant of the ICRP model into the thyroid $\left(T_{1 / 2}=\ln 2 / 0.8316=0.83\right.$ days $)$, but compatible with our model based on a capacity limited uptake carrier in combination with an additional first order renal elimination $\left(T_{1 / 2}=\ln 2 / 1.9404=0.357\right.$ days, i.e., 2 days corresponds to 5.6 * half-times). Therefore, the iodine blockade should be expected to be effective mainly during the first two days after radioiodine intake. Moreover, the protective efficacy for the period up to 10 days can practically be considered to be identical with the value for a period till infinity. 
- Table 2 Efficacy of iodine blockade $(100 \mathrm{mg})$ calculated using 3 different models. Model 1 (basic model): Protection only by competition of radioiodine and stable iodine at the carrier site. Model 2 and 3: In addition to model 1 , total iodine uptake block is achieved when the gland is saturated with iodine (saturation value from the literature for model 2 and calculated from empirical data for model 3). The doses have been calculated for a radioiodine intake of $700000 \mathrm{~Bq}$ given directly into the central compartment The efficacy of the iodine blockade is calculated according to the formula Efficacy $=1$ - (dose with blockade / dose without blockade).

\begin{tabular}{|l|l|l|c|}
\hline & Model 1 & Model 2 & Model 3 \\
\hline Dose without blockade after 1 d (mSv) & 316.2 & 316.2 & 316.2 \\
\hline Dose with blockade after 1 d (mSv) & 107.3 & 4.04 & 5.159 \\
\hline Blockade efficacy after 1 d & 0.661 & 0.987 & 0.984 \\
\hline Dose without blockade after 10 d (mSv) & 335.5 & 335.5 & 335.5 \\
\hline Dose with blockade after 10 d (mSv) & 134.6 & 4.04 & 5.159 \\
\hline Blockade efficacy after 10 d & 0.599 & 0.988 & 0.985 \\
\hline Onset time of total uptake block (min) & - & 39.46 & 50.50 \\
\hline
\end{tabular}

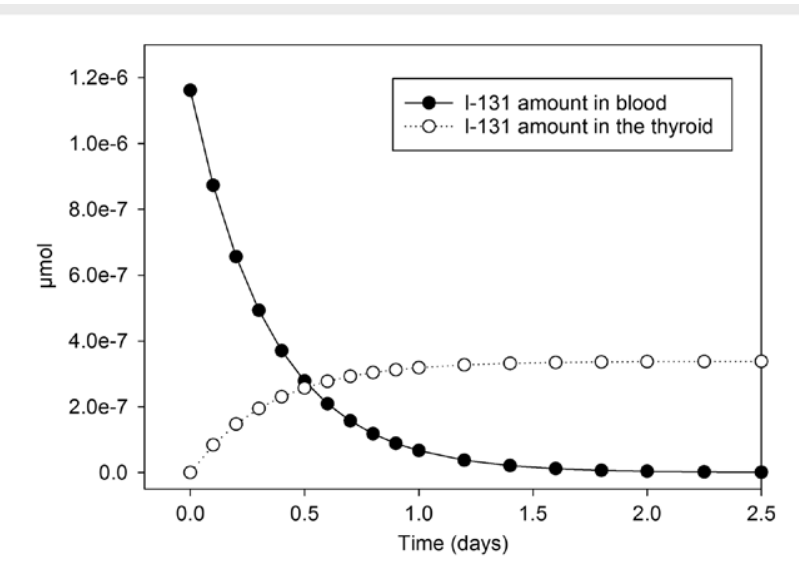

- Fig. 2 Time course of the amount of radioiodine in the central compartment ("blood") and the total amount incorporated into the thyroid. The values in $\mu \mathrm{mol}$ corresponds to an acute intake of $700000 \mathrm{~Bq}$.

The protective efficacies for the first day or the period up to 10 days are the overall result of the uptake inhibition by competition at the carrier site that is however decreasing over time, as stable iodine is rapidly excreted through the kidney. This means that if considering different period intervals after the administration of $100 \mathrm{mg}$ stable iodine, the efficacy substantially decreases over time. The uptake of more than $80 \%$ of the radioiodine is prevented during the first $3 \mathrm{~h}$, but only $31 \%$ from the $12^{\text {th }}$ to $24^{\text {th }}$ hour ( $>$ Fig. 3 ) With decreasing concentrations of stable iodine in the central compartment over time the uptake into the gland approaches again a pseudo first order kinetic similarly applicable to stable and radioactive iodine associated with a loss of competition and protective efficacy.

Assuming an additional protective effect with a total block of the uptake when the gland is totally saturated markedly increases the efficacy of a blockade by $100 \mathrm{mg}$ stable iodine to $98.8 \%$ (model 2 ). The onset of the total uptake block occurs at 39 min after stable iodine administration. The protective efficacy calculated using model

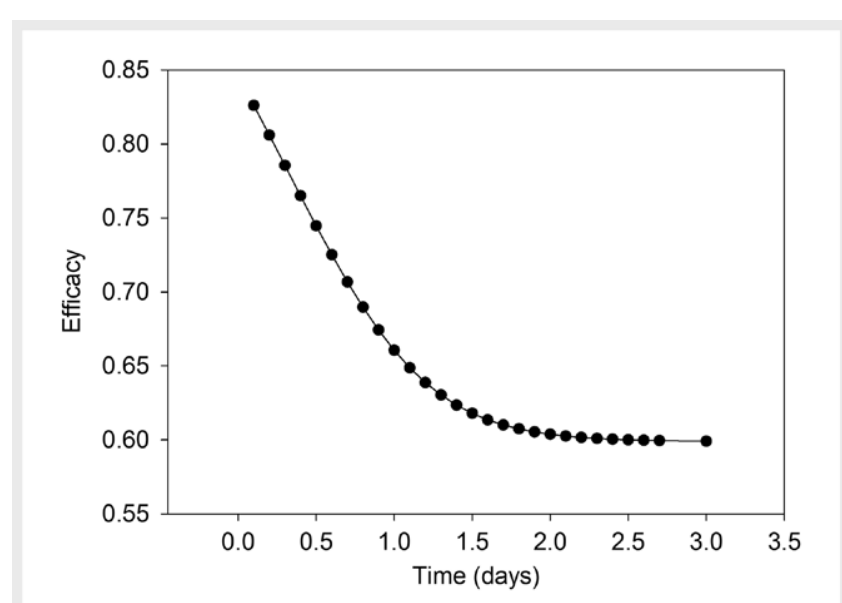

-Fig. 3 Time course of the cumulative efficacy of iodine blockade with $100 \mathrm{mg}$ stable iodine administered once simultaneously with acute radioiodine exposure. Efficacy $=1$ - (thyroid dose with iodine blockade/thyroid dose without iodine blockade) for every time point.

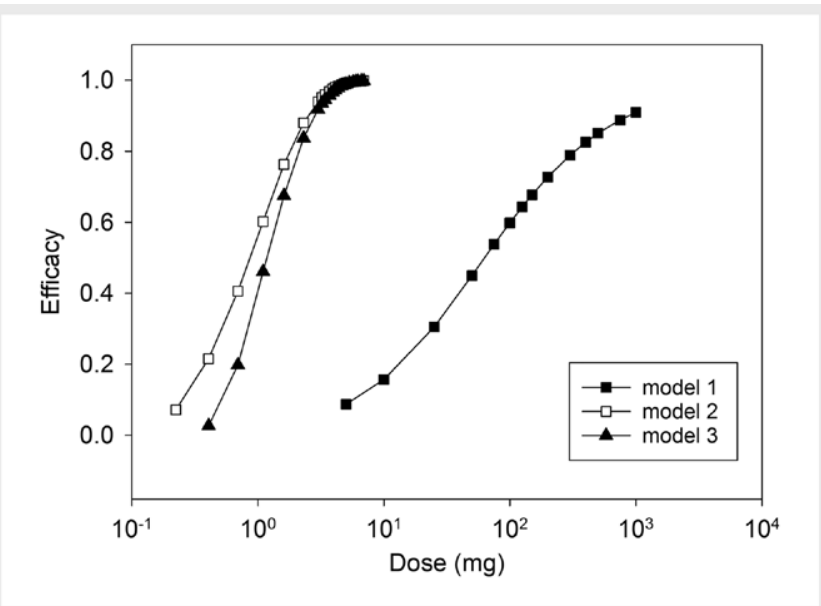

- Fig. 4 Dose efficacy curves for different single doses of stable iodine administered simultaneously with an acute radioiodine exposure resulting from the application of the different models.

3 is only marginally lower (98.5\%) with an onset time of 51 min for the occurrence of a total uptake block. There is no difference between the protective efficacy after 1 day or 10 days ( $>$ Table 2 ). This latter finding is easily explained by the early occurrence of the total uptake block within the first hour after stable iodine administration.

\section{Estimation of the protective efficacy of different single doses of stable iodine}

In model 1 , for a radioiodine intake of $700000 \mathrm{~Bq}$ the dose could be reduced from $335 \mathrm{mSv}$ to $135 \mathrm{mSv}$ for the period up to 10 days by $100 \mathrm{mg}$ stable iodine administered once at the time of the acute radioiodine exposure. This corresponds to an efficacy of $59.9 \%$ as described in the previous section.

Efficacy was lower for lower doses of stable iodine (e. g., $8.7 \%$ for $5 \mathrm{mg}$ ) and could be increased by increasing the dose (e. g., 
- Table 3 Median effective doses $\left(\mathrm{ED}_{50}\right)$ of the protective efficacy for the first day or the period up to 10 days after an acute radioiodine exposure and onset times of a total uptake block of the thyroid caused by the saturation of the gland depending on the dose of stable iodine administered at the time of acute radioiodine exposure.

\begin{tabular}{|l|l|c|c|}
\hline & Model 1 & Model 2 & Model 3 \\
\hline $\mathrm{ED}_{50}$ (mg stable iodine) 1 day & 50.11 & 2.70 & 3.62 \\
\hline $\mathrm{ED}_{50}$ (mg stable iodine) 10 days & 64.4 & 2.70 & 3.62 \\
\hline $\begin{array}{l}\text { Onset time total block (min) } 5 \mathrm{mg} \\
\text { stable iodine }\end{array}$ & - & 173.16 & 233.28 \\
\hline $\begin{array}{l}\text { Onset time total block (min) } 25 \mathrm{mg} \\
\text { stable iodine }\end{array}$ & - & 58.58 & 75.43 \\
\hline $\begin{array}{l}\text { Onset time total block (min) } 50 \mathrm{mg} \\
\text { stable iodine }\end{array}$ & - & 45.72 & 58.68 \\
\hline $\begin{array}{l}\text { Onset time total block (min) } \\
100 \mathrm{mg} \text { stable iodine }\end{array}$ & - & 39.46 & 50.50 \\
\hline $\begin{array}{l}\text { Onset time total block (min) } \\
200 \mathrm{mg} \text { stable iodine }\end{array}$ & - & 36.27 & 46.47 \\
\hline $\begin{array}{l}\text { Onset time total block (min) } \\
500 \mathrm{mg} \text { stable iodine }\end{array}$ & - & 34.42 & 44.05 \\
\hline $\begin{array}{l}\text { Onset time total block (min) } \\
1000 \mathrm{mg} \text { stable iodine }\end{array}$ & - & 33.80 & 43.26 \\
\hline
\end{tabular}

$72.8 \%$ for $200 \mathrm{mg}$, up to $91 \%$ for $1000 \mathrm{mg}$ ) ( $\vee$ Fig. 4). Similarly, the uptake fraction of radioiodine into the thyroid decreased from $11.7 \%$ after administering $100 \mathrm{mg}$ of stable iodine to $7.9 \%$ with $200 \mathrm{mg}$ and even $2.6 \%$ with $1000 \mathrm{mg}$. The median effective dose $\mathrm{ED}_{50}$ of stable iodine to reduce the equivalent dose to the thyroid was determined with $64 \mathrm{mg}$. Based on the equivalent dose values after 1 day (efficacy $66.1 \%$ ), the $\mathrm{ED}_{50}$ was determined with $50 \mathrm{mg}$ ( $\triangleright$ Table 3). For the different doses of stable iodine, efficacy was similar after the intake of $100 \mathrm{~Bq}$ or $5^{*} 10^{6} \mathrm{~Bq}$ radioiodine.

Using model 2 or 3 much lower $\mathrm{ED}_{50}$ values were determined for protective efficacy ( 2.70 or $3.62 \mathrm{mg}$, respectively) and there was no difference whether efficacy after 1 day or 10 days was considered ( $\vee$ Fig. 4, $\triangleright$ Table 3 ).

In models 2 and 3 the onset time of the total radioiodine uptake block was shortened by increasing the dose of stable iodine. It was calculated in a range of several hours for low doses (e. g., in model 2 for $5 \mathrm{mg}: 173 \mathrm{~min}$ and in model 3: $233 \mathrm{~min}$ ) and for dosages between $100 \mathrm{mg}$ and $1000 \mathrm{mg}$ stable iodine in the range of 30 to 40 min in model 2 and 40 to roughly 50 min in model 3 ( Table 3 ).

\section{Estimation of protective efficacy of a single stable iodine dose depending on the time of blockade initiation}

Protective efficacy in model 1 is maximal when stable iodine is administered simultaneously to acute radioiodine exposure. For model 1 , the time-efficacy relation is not symmetrical in relation to the time point of acute radioiodine exposure ( $\vee$ Fig. 5 ): Whereas efficacy exceeds $40 \%$ if stable iodine is given within a time frame starting $9 \mathrm{~h}$ before acute radioiodine exposure, it decreases more rapidly thereafter $(100 \mathrm{mg}$ administered $9 \mathrm{~h}$ after exposure leads to an efficacy of only $30 \%$ ). Following the administration of $100 \mathrm{mg}$ stable iodine, about $45 \mathrm{mg}$ will remain in the central compartment after $9 \mathrm{~h}$ at the time of radioiodine exposure. Therefore, efficacy is

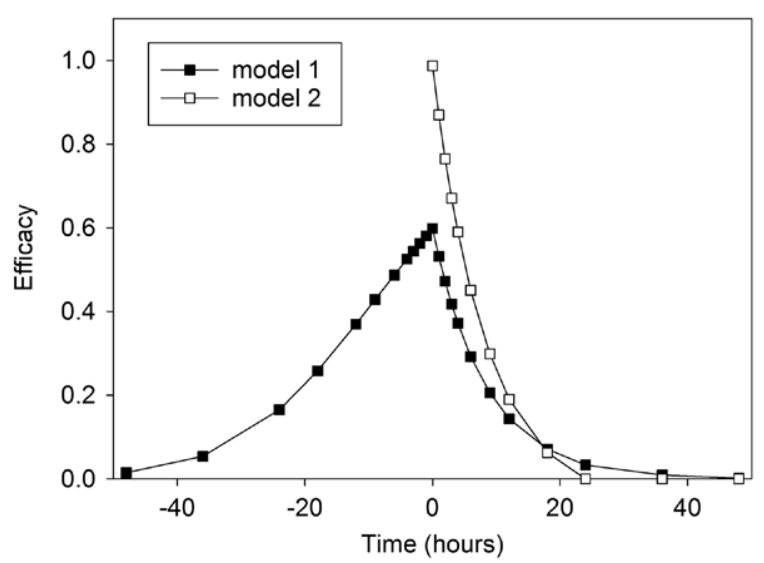

- Fig. 5 Time course of efficacy of iodine blockade with $100 \mathrm{mg}$ stable iodine administered once at different time points before or after acute radioiodine exposure at $\mathrm{t}=0 \mathrm{~h}$. Efficacy $=1-$ (thyroid dose with iodine blockade / thyroid dose without iodine blockade). Results for model 3 are not displayed for clarity as the curve is quite similar to model 2.

in a comparable order of magnitude as an iodine blockade performed with $50 \mathrm{mg}$ stable iodine administered simultaneously to acute radioiodine exposure (see also for comparison the results in the section "protective efficacy of repetitive doses" and $>$ Fig. 6). If stable iodine is administered $9 \mathrm{~h}$ after radioiodine exposure, radioactivity that has already entered the gland at the time starting the blockade amounts to roughly $70 \%$ of the maximum (intake of $700000 \mathrm{~Bq}$ leads to $316 \mathrm{mSv}$ after 1 day without blockade and to $220 \mathrm{mSv}$ after $100 \mathrm{mg}$ stable iodine given after $9 \mathrm{~h}$ ).

For models 2 and 3 , perfect protective efficacy would be expected if saturation of the gland is attained at the time of radioiodine exposure. Administering $100 \mathrm{mg}$ stable iodine, this state is reached in less than $1 \mathrm{~h}$ ( $\vee$ Table 2 ). This mathematical result is however not plausible and meaningful from a medical point of view, as the WolffChaikoff effect is a reversible temporary phenomenon. Therefore, efficacy was not calculated (and not displayed in > Fig. 5) for stable iodine administered prior to radioiodine exposure. If iodine blockade is started after radioiodine exposure, efficacy calculated using model 2 or 3 rapidly diminishes at a comparable rate as for model 1 , with the difference that the maximum efficacies are higher (over $98 \%$ for model 2 and 3 vs. 59.9\% for model 1) ( $\triangleright$ Fig. 5).

\section{Estimation of the protective efficacy of repetitive doses of stable iodine after acute radioiodine exposure using model 1}

Protective efficacy was computed for the period up to 10 days after radioiodine exposure applying model 1 . The thyroid dose resulting from the acute intake of $700000 \mathrm{~Bq}$ of radioiodine could be reduced from $335 \mathrm{mSv}$ to $135 \mathrm{mSv}$ (efficacy $59.9 \%$ ) by a single dose of $100 \mathrm{mg}$ stable iodine and to $119.8 \mathrm{mSv}$ (efficacy $64.3 \%$ ) by repeating the administration of stable iodine after $24 \mathrm{~h}$. A third dose of $100 \mathrm{mg}$ stable iodine $48 \mathrm{~h}$ after radioiodine intake did not substantially improve the efficacy of the blockade (64.7\%) ( Fig. 6). 

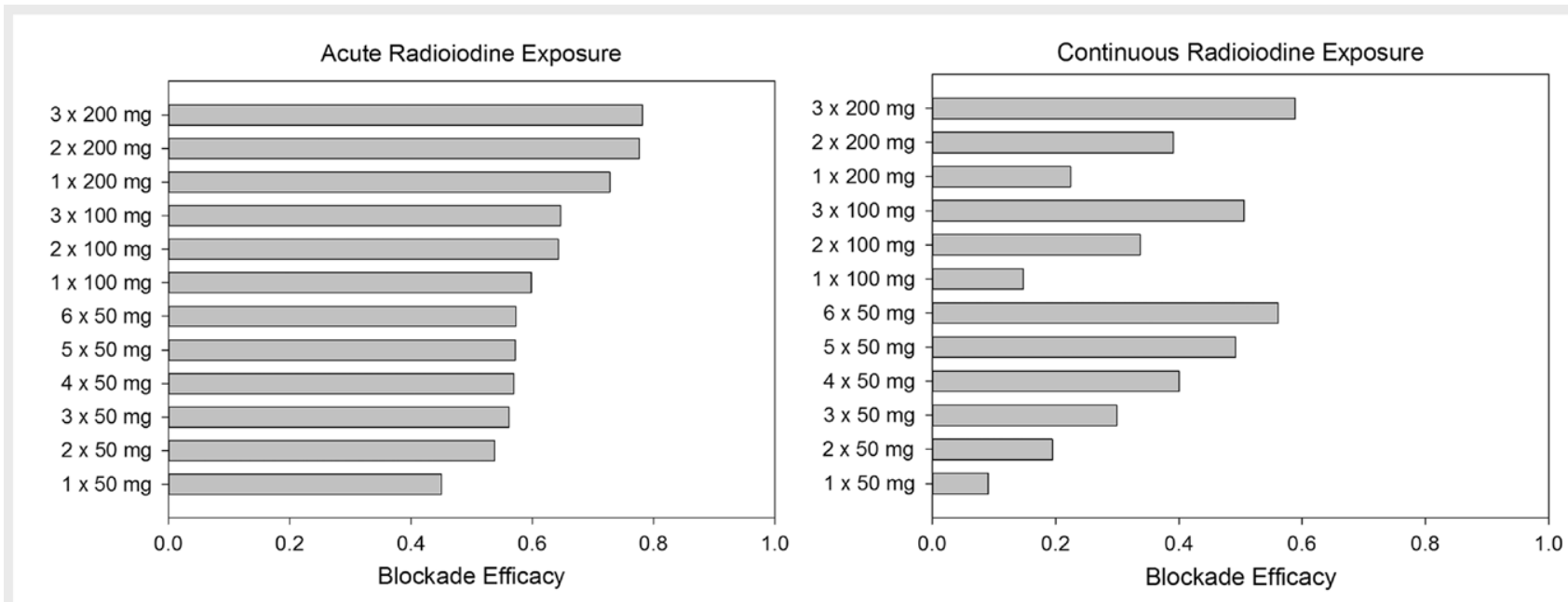

Fig. 6 Protective efficacy of different dosage schemes of stable iodine in the case of acute or continuous radioiodine exposures for 3 days computed by using the basic model 1 . lodine blockade was started at the beginning of radioiodine exposure in all cases. Doses of $100 \mathrm{mg}$ or $200 \mathrm{mg}$ of stable iodine were administered at intervals of $24 \mathrm{~h}$ and doses of $50 \mathrm{mg}$ every $12 \mathrm{~h}$.

This could be expected as most of the radioiodine has already been taken up into the gland after $48 \mathrm{~h}$.

Repetitive administrations of $200 \mathrm{mg}$ of stable iodine was more effective than $100 \mathrm{mg}$ (after 2 doses $77.7 \%$ for $200 \mathrm{mg}$ vs. $64.3 \%$ for $100 \mathrm{mg}$ ). Again repetitive doses did not substantially improve efficacy (• Fig. 6).

Splitting higher doses and conversely shortening the dosage interval is associated with a poorer efficacy according to our model 1 , as seen in the case of administering repetitive doses of $50 \mathrm{mg}$ stable iodine ( $\vee$ Fig. $\mathbf{6}$ ). Thus, it seems that in the case of an acute radioiodine exposure, the best results are obtained by rapidly achieving high stable iodine blood concentrations at a time when radioiodine concentrations in the blood are high.

\section{Estimation of the protective efficacy of stable iodine in case of continuous radioiodine exposure using model 1}

In the case of a continuous radioiodine exposure over 3 days with $230000 \mathrm{~Bq} / \mathrm{d}$, the administration of a single dose of $100 \mathrm{mg}$ stable iodine administered at the beginning of radioiodine exposure reduced the thyroid dose from $330.7 \mathrm{mSv}$ to $281.7 \mathrm{mSv}$. Thus, iodine blockade had a substantially lower efficacy than in the case of an acute radioiodine exposure ( 14.8 vs. $59.9 \%$ ). Efficacy could be substantially improved by daily repetitive stable iodine administrations, but even after 3 doses there was still a gap with the efficacy in case of an acute radioiodine exposure (efficacy for $3 \times 100 \mathrm{mg}$ : 50.6 vs. $64.7 \%$ ) ( Fig. 6).

At the difference from an acute radioiodine exposure, efficacy could be slightly improved by decreasing the individual doses and conversely shortening the dosage intervals (efficacy $56.1 \%$ for $50 \mathrm{mg}$ given every $12 \mathrm{~h}$ for 3 days vs. $50.6 \%$ for $100 \mathrm{mg}$ given every $24 \mathrm{~h}$ for 3 days) ( Fig. 6). Efficacy could be further improved by increasing the total dosage $(3 \times 200 \mathrm{mg}$ instead of $3 \times 100 \mathrm{mg}, 58.9$ vs. $50.6 \%)$. Thus, for acute as well as continuous radioiodine exposure the most effective way to enhance efficacy according to our model 1 is to administer larger individual doses of stable iodine, exceeding the usually recommended dose of $100 \mathrm{mg}$.

\section{Application of the model to the Castle Bravo nuclear testing incident: What if potassium iodide tablets had been available?}

With a single dose of stable iodine $(100 \mathrm{mg})$ administered immediately with the beginning of radioiodine exposure, the internal thyroid dose could have been reduced from $7600 \mathrm{mSv}$ to $6460 \mathrm{mSv}$ according to our model 1 . Additional doses of $100 \mathrm{mg}$ given on day 2 ( $24 \mathrm{~h}$ after the beginning of radioiodine exposure) and on day $3 \mathrm{had}$ further reduced the dose to $5039 \mathrm{mSv}$ and $3724 \mathrm{mSv}$ respectively. This confirms that in the case of high radioiodine exposure associated with high activity fallout, iodine blockade alone is not an alternative to further protective measures as sheltering and/or evacuation.

\section{Application of the model to a victim of the Fukushima incident: What if potassium iodide tablets had been administered at different dosages?}

For the evacuee with the highest thyroid activity measured we calculated a corresponding constant radioiodine intake of $1868 \mathrm{~Bq}$ / day for an exposure period of 7 days. The equivalent thyroid dose absorbed without iodine blockade was determined with $6.47 \mathrm{mSv}$. This value is very low and would hardly justify the initiation of an iodine blockade. Therefore the following findings are only intended to exemplify the impact of different dosage schemes on the protective efficacy and should not be interpreted as an a posteriori recommendation that stable iodine should have been administered in this particular case. The time course of radioiodine in the central compartment ("blood") and the total amount incorporated into the thyroid without or with iodine blockade is shown in \ Fig. 7.

Compared to an exposure period of 3 days, the protective efficacy of similar single or repetitive doses of stable iodine is lower if radioiodine exposure time is extended to 7 days, as the time period without protection is longer (e. g., the efficacy for $1 \times 100 \mathrm{mg}$ 


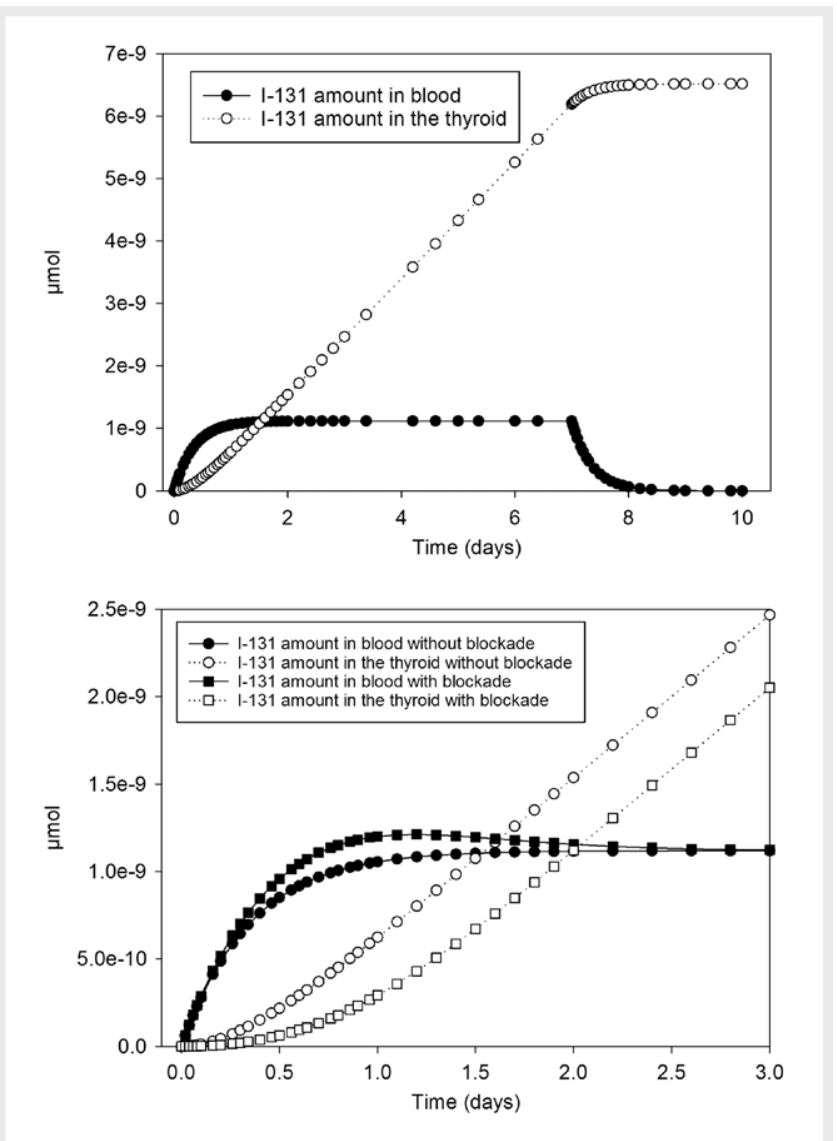

- Fig. 7 Time course of the amount of radioiodine in the central compartment ("blood") and the total amount incorporated into the thyroid $(\mu \mathrm{mol})$ in the case of a continuous radioiodine exposure over 7 days with an intake of $1868 \mathrm{~Bq} /$ day without iodine blockade (upper Figure). The time course over the first 3 days is shown without or with iodine blockade with a single dose of $100 \mathrm{mg}$ stable iodine administered at the beginning of radioiodine exposure (lower Figure).

stable iodine given at the beginning of radioiodine exposure amounts to 0.148 for a 3 day exposure vs. 0.064 for a 7 day exposure) (compare $\triangleright$ Fig. 6 and $\triangleright$ Table 4 ).

Larger doses administered at the same dosage interval enhances protective efficacy (efficacy of 0.195 for $2 \times 200 \mathrm{mg}$ at $24 \mathrm{~h}$ interval vs. 0.140 for $2 \times 100 \mathrm{mg}$ ). But splitting a total dose administered into lower single doses given at shorter intervals seems even more preferable ( $\triangleright$ Table 4$)$.

If only one single dose of stable iodine is available and longer lasting continuous radioiodine exposure is to be expected, protective efficacy is improved if iodine blockade is delayed for 1 to 2 days until the radioiodine level in blood has reached a plateau and therefore its maximal concentration ( $\triangleright$ Fig. 7). It is however not meaningful to delay stable iodine administration more than 2 days. If given shortly before evacuation, efficacy is less (e. g., efficacy after $1 \times 100 \mathrm{mg}$ given on day 6 if evacuation occurs after 7 days is 0.074 vs. 0.093 if given on day 3) ( $\triangleright$ Table 4).

If radioiodine exposure duration cannot be predicted and several stable iodine doses are available that nevertheless may be in- sufficient for a dose every day, protective efficacy can be improved by extending dosage intervals (e. g., $100 \mathrm{mg}$ given at $\mathrm{t}=0$ and $48 \mathrm{~h}$ is more effective than at $\mathrm{t}=0$ and $24 \mathrm{~h}$ ) ( $\triangleright$ Table 4 ).

\section{Discussion}

In the original ICRP model for radioiodine the uptake into the thyroid occurs according to a first order kinetic although it is known that the transport through the cellular membrane is an active process mediated by a carrier. For practical purposes this seems to be a legitimate and pragmatic approach simplifying mathematics, as radioiodine has a high specific activity, and even amounts used in nuclear medicine for the therapy of thyroid diseases (400-3000 $\mathrm{MBq}$, up to several thousand $\mathrm{MBq}, 8000 \mathrm{MBq}$ ) [38, 39] leads to molar concentrations in the extracellular space and blood (8000 $\mathrm{MBq}$, roughly $0.01 \mu \mathrm{mol} / 16 \mathrm{I}=6.25^{*} 10^{-4} \mu \mathrm{mol} / \mathrm{l}$ ) that are far below the $K_{m}$ values of the thyroid membrane transporter $(9 \mu \mathrm{mol} / \mathrm{l})$ [24]. However, this is not legitimate to describe the kinetics of very high doses of stable iodine as used for iodine blockade, as the administration of $100 \mathrm{mg}$ iodine in the extracellular space will result in an initial concentration of $49 \mu \mathrm{mol} / \mathrm{l}$ exceeding the $\mathrm{Km}$ value of the carrier. That's why for our simulations, we used a mechanistic approach and integrated in our model an active carrier transport described by Michaelis-Menten-kinetics [40].

A valid compartmental model requires an adequate structure and correct parameters describing exchange processes between the compartments. For the iodine membrane carrier in mouse, rat and sheep thyroids $\mathrm{K}_{\mathrm{m}}$ values of $2-4^{*} 10^{-5} \mu \mathrm{mol} / \mathrm{l}$ have been described [40] and it seems that for varying stimulations by TSH the $\mathrm{K}_{\mathrm{m}}$ values remain constant. For the human iodine carrier in the thyroid lower $K_{m}$ values have been given $\left(9^{*} 10^{-6} \mu \mathrm{mol} / \mathrm{l}\right)$ [24] and that is the value we used in our models. We deduced the maximum transport capacity from this $\mathrm{K}_{\mathrm{m}}$ value and the rate constant given in the ICRP biokinetic model and kept this value constant over the simulations. However, it is known that the amount of carrier material in thyroid tissue may vary in a rather wide range, leading to uncertainties for the maximum transport capacity. This is also well illustrated by estimations of the extrarenal mainly thyroid clearance of radioiodine from serum in man. Whereas for euthyroid patients the clearance is given with $26.3 \pm 5.2 \mathrm{ml} / \mathrm{min}$ (mean \pm standard error), it amounts to $154.6+19.5 \mathrm{ml} / \mathrm{min}$ in patients with hyperthyroidism [41]. In another study, in 3 normal patients the clearance was determined with $7.2,18.6$ and $28.7 \mathrm{ml} / \mathrm{min}$ respectively (400\% difference) [42]. A comparison of the doses calculated with our model 1 and the values given by the IMBA software based on internationally accepted ICRP models nevertheless indicates that the parameters in our modelling seems to be in a valid range. The discrepancies between the results for high intake activities is to be expected from saturation mechanisms and this is a prerequisite for the usefulness of our models in simulating an iodine blockade.

In the case of an acute radioiodine exposure and administration of a single dose of $100 \mathrm{mg}$ of stable iodine, the dosage usually recommended, model 1 predicts a protective efficacy of about $60 \%$. This is less than the figures of over $90-95 \%$ often reported for studies on volunteers [29]. However, lower figures have also been reported $(88.7 \%$ for $100 \mathrm{mg}$ administered $24 \mathrm{~h}$ before exposure, $63.8 \%$ if administered $2 \mathrm{~h}$ after exposure) and it was suggested that 
- Table 4 Protective efficacy of different dosage schemes of stable iodine in the case of a continuous radioiodine exposure lasting for 7 days computed by using the basic model 1. The dose values are based on the activity measured in an evacuee who had stayed in Fukushima from March 11 to 18,2011 (source [37]).

\begin{tabular}{|c|c|c|c|}
\hline lodine dosage & Time of stable iodine administration (h) & Dose (mSv) & Efficacy \\
\hline No blockade & & 6.47 & 0.000 \\
\hline $1 \times 50 \mathrm{mg}$ & 0 -- -- -- -- -- -- -- -- -- -- -- -- -- & 6.22 & 0.039 \\
\hline $2 \times 50 \mathrm{mg}$ & 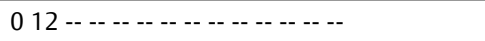 & 6.00 & 0.072 \\
\hline $3 \times 50 \mathrm{mg}$ & 01224 -- -- -- -- -- -- -- -- -- & 5.77 & 0.108 \\
\hline $4 \times 50 \mathrm{mg}$ & 0122436 -- -- -- -- -- -- -- -- & 5.53 & 0.145 \\
\hline $5 \times 50 \mathrm{mg}$ & 012243648 & 5.29 & 0.183 \\
\hline $6 \times 50 \mathrm{mg}$ & 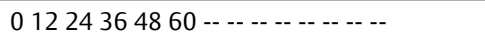 & 5.05 & 0.220 \\
\hline $1 \times 100 \mathrm{mg}$ & 0 -- -- -- -- -- & 6.06 & 0.064 \\
\hline $2 \times 100 \mathrm{mg}$ & 024 -- -- -- -- -- & 5.56 & 0.140 \\
\hline $3 \times 100 \mathrm{mg}$ & 02448 -- -- -- & 5.05 & 0.219 \\
\hline $4 \times 100 \mathrm{mg}$ & 0244872 -- --- & 4.54 & 0.298 \\
\hline $5 \times 100 \mathrm{mg}$ & 024487296 -- -- & 4.03 & 0.377 \\
\hline $6 \times 100 \mathrm{mg}$ & 024487296120 -- & 3.53 & 0.455 \\
\hline $7 \times 100 \mathrm{mg}$ & 024487296120144 & 3.13 & 0.516 \\
\hline $2 \times 100 \mathrm{mg}$ & 0 -- 48 -- -- -- -- & 5.46 & 0.156 \\
\hline $3 \times 100 \mathrm{mg}$ & 0 -- 48 -- 96 -- -- & 4.86 & 0.249 \\
\hline $4 \times 100 \mathrm{mg}$ & $0--48--96--144$ & 4.38 & 0.323 \\
\hline $1 \times 100 \mathrm{mg}$ & 6 -- -- -- -- -- -- -- -- --- -- -- -- -- -- --- -- -- & 5.96 & 0.079 \\
\hline $1 \times 100 \mathrm{mg}$ & -- 12 -- -- -- -- --- -- -- -- -- --- -- -- -- -- -- --- -- & 5.91 & 0.086 \\
\hline $1 \times 100 \mathrm{mg}$ & -- --18 -- -- -- -- -- -- -- -- -- -- -- -- -- -- -- -- & 5.89 & 0.090 \\
\hline $1 \times 100 \mathrm{mg}$ & -- -- --24 -- -- -- -- -- -- -- -- -- -- -- -- -- -- -- & 5.88 & 0.092 \\
\hline $1 \times 100 \mathrm{mg}$ & -- -- -- 36 -- -- -- -- -- -- -- -- -- -- -- -- -- & 5.87 & 0.093 \\
\hline $1 \times 100 \mathrm{mg}$ & -- -- -- -- -- 48 -- -- -- -- -- -- -- -- -- -- -- - - - - & 5.86 & 0.093 \\
\hline $1 \times 100 \mathrm{mg}$ & -- -- -- -- -- -- -- 72 -- -- -- -- -- -- -- - - - - - - & 5.86 & 0.093 \\
\hline $1 \times 100 \mathrm{mg}$ & "-- -- -- -- -- -- -- -- -- -- -- -- -- -- 144 -- & 5.99 & 0.074 \\
\hline $1 \times 200 \mathrm{mg}$ & 0 -- -- -- -- -- -- & 5.85 & 0.096 \\
\hline $2 \times 200 \mathrm{mg}$ & 024 -- -- -- -- & 5.21 & 0.195 \\
\hline $2 \times 200 \mathrm{mg}$ & 0 -- 48 -- -- -- -- & 5.00 & 0.227 \\
\hline $3 \times 200 \mathrm{mg}$ & 0 -- 48 -- 96 -- -- & 4.15 & 0.358 \\
\hline
\end{tabular}

protective efficacy has often been overestimated for young adults and even more for children [43]. Our results confirm that the competition of radioiodine and stable iodine at the carrier site of the membrane seems to be the main protective mechanism in iodine blockade, but that additional effects are probably involved $[9,44]$. High iodine concentrations are known to inhibit the hormonal synthesis and integration of iodine into thyroglobulin (Wolff-Chaikoff effect) [45]. This might contribute to increase the free intracellular radioiodine concentration, concomitantly enhancing the gradient between the intra- and extracellular space, and hence the amount of radioiodine flowing back out of the cells by passive diffusion, explaining the protective effect. Although the thyroid follicular epithelium is morphologically and functionally polarized with an unidirectional transport of iodide from the basolateral through the apical membrane into the follicular lumen [46], thyroid cells expresses also transporters and channels common to many epithelia, and it has been shown that iodide may cross membranes using the same ways as chloride $[47,48]$. Several models dealing with iodide trapping include a pathway out of the follicular cells into plasma described by first order kinetics [49-51]. We modeled the Wolff-
Chaikoff effect in model 2 and 3 by a saturation mechanism. The iodine amounts needed to saturate the gland seems quite small ( $350 \mu \mathrm{g}$ as reported in [27] and used in our model 2) compared to the mean daily iodine intake (about 150-250 $\mathrm{g} / \mathrm{d}$ ) and physiological uptake by the thyroid (about $70 \mu \mathrm{g} / \mathrm{d}$ ) [27, 52]. However, this is meaningful assuming a physiological regulation mechanism. It is worth mentioning that thyroidal iodine saturation thresholds may show large variations among populations due in part to different diets and daily iodine intakes [53]. It has been described that the blocking of the thyroid occurs within several hours after taking the stable iodine $[9,10]$. A time frame of 30-90 min has been reported by Ramsden et al. [27] and this corresponds well to our computations when applying our models 2 or 3 . However, it must be assumed that in reality the activation of the Wolff-Chaikoff effect is a progressive process, whereas for modelling purposes it was artificially "switched on" once the iodine saturation amount was reached. The Wolff-Chaikoff effect is moreover usually a temporary effect that is fading after $24-48 \mathrm{~h}[9,10]$, although vulnerable patients with a thyroidal dysregulation may fail to escape this effect 
developing longer lasting hypothyroidism [20]. It has been reported that this escape phenomenon is caused by an iodine-induced decrease of iodine transport through down-regulation of the carrier in the membrane reducing the intracellular availability of iodine $[54,55]$. It has been described that the mRNA encoding the carrier and protein expression decreases, so that the mechanism seems at least in part to operate at a transcriptional and post-transcriptional level $[54,56]$. This down-regulation of the carrier in the membrane would on the other side be associated with a decrease of the maximum transport capacity $T_{\max }$ in our model. These phenomena are not represented in our modelling, as we did not find information precise enough to decide on a "switch-off" time that could be justified or for an adjustment of the maximum transport capacity for iodine through the membrane. This is particularly limiting the usefulness of the models 2 and 3 for the simulations of repetitive stable iodine administrations in the case of continuous radioiodine exposure. That's why for these simulations we used model 1 , being nevertheless aware that this is a very conservative approach with an underestimation of protective efficacy.

Our model permits nevertheless to deduce general rules about dosage schemes for different radioiodine exposure scenarios. As a general rule, it seems that following a short term acute radioiodine exposure it is preferable to administer a larger single dose of stable iodine as soon as possible. It is not advisable to split the dose and repetitive dosages do not substantially improve efficacy. On the contrary, in the case of a continuous radioiodine exposure, whether by inhalation or ingestion, a single even large dose of stable iodine is much less effective than after an acute radioiodine exposure and repetitive administrations seem advisable. In this case splitting the total available dose and shortening the dosage intervals enhance efficacy. In case of a longer lasting radioiodine exposure, the dosage scheme associated with the optimum efficacy also depends on the amount of stable iodine available for each exposed victim. The decisions on the best dosage scheme must therefore take into account, or in a real scenario appraise as far as it is practically possible, radioiodine exposure duration and its pattern (e. g., constant exposure or exposure peaks), the timelines necessary for evacuation as well as the antidote amounts immediately available for administration.

It has been recommended not to increase the dosage of stable iodine over $100-200 \mathrm{mg}[29,57]$ and it was even stated that radioiodine uptake can be markedly suppressed by only $30 \mathrm{mg}$ of stable iodine [58]. On the other side, applying our model 1 for cases of acute or continuous exposure seems to indicate that protective efficacy could be improved by increasing the dosage of stable iodine over the usually recommended dose of $100 \mathrm{mg}$. Lugol's solution has been used for a long time in patients planned for thyroidectomy and historically Plummer used $80-320 \mathrm{mg}$ daily for 10 days as a well established treatment [59]. Even higher daily dosages up to $800 \mathrm{mg}$ daily have been reported in the literature [60,61]. However, for the purpose of iodine blockade aimed at a large heterogeneous population including vulnerable persons without prior individual medical assessment the systemic chemical toxicity of iodine should be carefully considered. A dose of $200 \mathrm{mg}$ is still below the NOAEL (no observed adverse effect level) value reported for a single dose in humans with $3.4 \mathrm{mg} / \mathrm{kg}$ (i. e., $3.4 \times 70 \mathrm{~kg}$ body weight $=238 \mathrm{mg}$ ) [62]. Lethal oral poisonings have been associated with iodine doses of 1200 to $9500 \mathrm{mg}(17-120 \mathrm{mg} / \mathrm{kg})[11,63]$, although the ingestion of higher doses $(15000 \mathrm{mg}$ ) have been survived [64]. The LOAEL (lowest observed adverse effect level) for serious effects (in this case death) in humans is given with $17 \mathrm{mg} / \mathrm{kg}$ [11] and this would correspond to $1,190 \mathrm{mg}$ in an adult of $70 \mathrm{~kg}$ body weight. Therefore, even if administering only once a single dose, it seems prudent not to exceed $200 \mathrm{mg}$ of stable iodine. Additional factors, i. e., the NOAEL and LOAEL values for repetitive administrations should also be considered. The NOAEL for iodine in humans for a period of 7 days $(0.46 \mathrm{mg} / \mathrm{kg} / \mathrm{d} \times 70 \mathrm{~kg}=32 \mathrm{mg} / \mathrm{d})$ $[11,65]$ is lower than for a single administration $(3.4 \mathrm{mg} / \mathrm{kg} x$ $70 \mathrm{~kg}=238 \mathrm{mg})[11,62]$. Thus, pharmacological decisions on the optimal dosages for particular scenarios must be embedded and combined with an assessment of the expected radioiodine exposure level and time as well as the comprehensive plan how to manage the emergency situation, including if necessary the timelines for sheltering or evacuation.

The importance of emergency measures other than iodine blockade becomes also obvious when considering the Castle Bravo case. Applying our model shows that in that case, despite the protective efficacy of repetitive doses of stable iodine, the thyroid equivalent doses in the exposed victims would have remained very high. That's why the measured and expected intensity of radioiodine exposure must always be considered and included in the decision making. lodine blockade is not a stand-alone protective action and must not be considered as a substitute for further protective measures like e. g., sheltering and/or evacuation, even if this may reveal difficult when a larger number of victims is involved.

Our models and conclusions apply to an adult population. For predictions in children age-specific iodine models should be used [66]. Children and adolescents are found to have higher risks to develop thyroid diseases and cancer after radioiodine exposure. In comparison to adults, the gland is smaller and the radioiodine uptake and absorbed dose is higher. Therefore, iodine blockade is particularly important for thyroid protection $[10,16]$. The same applies to breastfeeding mothers as well as pregnant women in order to protect the fetus, as radioiodine readily crosses the placenta $[10,16]$. Simulations of iodine distribution and metabolism are possible with specific models developed for pregnancy and lactation [67]. Although there is a clear indication for iodine blockade in pregnant women, the capacity of the fetus to escape from the Wolff-Chaikoff effect is less and the iodine overload may cause fetal/ neonatal hypothyroidism $[68,69]$. The transplacental transfer of thyroxine from the mother to the fetus beyond the first trimester is limited by placental deiodinases whose activities increase with gestation [70]. In cases of fetal thyroid dysfunction however, it seems that placental deiodinases are inhibited and moreover the intracellular activation to triodothyroxine in the fetal brain activated, protecting the brain from permanent damage [70]. Among neonates of mothers having got an iodine blockade in 1986 in Poland following the Chernobyl accident only $0.37 \%$ ( 12 from a sample of 3214 newborns) showed hypothyroidism at birth and the anomalies have been reported to disappear $16-20$ days after birth $[10,71]$. Although these results suggest that iodine blockade is relatively well tolerated by the fetus, it is prudent to closely monitor the thyroidal hormonal status of pregnant women having got an iodine blockade as well as to closely follow up the newborn for thyroidal 
dysfunction. Although neonates, pregnant and breastfeeding women will most likely benefit from iodine blockade, the WHO recommends that they should not receive repeated stable iodine doses due to the risk of adverse effects [16].

\section{Conclusion}

Simulations based on biokinetic and dosimetric models may be an effective and efficient tool permitting to develop therapeutic dosage schemes for antidotes reserved to uncommon emergencies like nuclear or radiological incidents. The real challenge is to develop a model with a valid structure and in particular valid parameters. Our basic model 1 tends to underestimate the protective efficacy of iodine blockade and is thus very conservative. It should however also be remembered that newer findings indicate that the very high values often given in the past for protective efficacy might be overestimated particularly in young victims who are the most vulnerable [43]. So, it seems that our basic model could be valuable to establish general rules about dosage schemes with single or repetitive stable iodine administrations for a wide range of nuclear and radiological scenarios. However, additional aspects like the systemic chemical toxicity of iodine must always be taken into account and it seems that it is not recommended to use stable iodine dosages exceeding 100-200 mg. Moreover, the particular sensitivity of children, breastfeeding and pregnant women including the fetus must be considered. Despite all these restrictions, simulation results using our model may contribute to a more focused and efficient preparedness planning, and that even beyond only the field of antidote treatment by giving indications if further measures (e.g., evacuation) may be required.

\section{Conflicts of Interest and Sources of Funding}

The authors declare that they have no conflict of interest. There was no funding for this study. This article does not contain any studies with human or animal subjects.

\section{References}

[1] Wohni T. External doses from radioactive fallout: Dosimetry and levels. Submitted in partial fulfilment for the degree of Doktor ingenier. Department of Physics, Norwegian Institute of Technology, University of Trondheim; 1995

[2] Glasstone S, Dolan P]. The effects of nuclear weapons. Third edition, Washington DC: The United States Department of Defense and the United States Department of Energy, US Governemt Printing Office; 1977

[3] Simon SL, Bouville A, Land CE. Fallout from nuclear weapons tests and cancer risks. American Scientist 2006; 94: 48-57

[4] List RJ. World wide fallout from operation Castle. Washington DC: United States Department from Commerce; 1955

[5] Simon SL, Bouville A, Land CE et al. Radiation doses and cancer risks in the Marshall islands associated with exposure to radioactive fallout from Bikini and Enewetak nuclear weapons tests: Summary. Health Phys 2010; 99: 105-123
[6] Imanaka T, Hayashi G, Endo S. Comparison of the accident process, radioactivity release and ground contamination between Chernobyl and Fukushima-1. J Radiat Res 2015; 56: i56-i61

[7] National Cancer Institute. Estimated exposure and thyroid doses report. Download on the internetpage: Get the facts about exposure to I-131 radiation. 2015; https://www.cancer.gov/about-cancer/ causes-prevention/risk/radiation/i131-report-and-appendix

[8] Chabot G. Radiation basics. Fission, Fusion. Q10097 - Why are cesium-137, strontium- 90 , and iodine- 131 the fission products that get most talked about when many more fission products are produced in reactors? Health Physics Society 2016; https://hps.org/publicinformation/ate/q10097.html

[9] Geoffroy B, Verger P, Le Guen B. Pharmacocinétique de l'iode: revue des connaissances utiles en radioprotection accidentelle. Radioprotection 2000; 35: 151-174

[10] Verger P, Aurengo A, Geoffroy B et al. lodine kinetics and effectiveness of stable iodine prophylaxis after intake of radioactive iodine: A review. Thyroid. 2001; 11: 353-360

[11] Agency for Toxic Substances and Disease Registry (ATDSR). Toxicological profile for iodine. Atlanta: US Department of health and human services, Public Health Service, Agency for Toxic Substances and Disease Registry; 2004

[12] Kovari M. Effect of delay time on effectiveness of stable iodine prophylaxis after intake of radioiodine. J Radiol Prot 1994; 14: 131-136

[13] Berson SA, Yalow RS, Sorrentino J et al. The determination of thyroidal and renal plasma I-131 clearance rates as a routine diagnostic test of thyroid dysfunction. J Clin Invest 1952; 31: 141-158

[14] Henriksen T, Hole EO, Sagstuen E et al. (Biophysics Group at UiO). Radiation and health. University of Oslo, Faculty of mathematics and natural sciences, Department of physics; 2014

[15] Rump A, Stricklin D, Lamkowski A et al. Reconsidering current decorporation strategies after incorporation of radionuclides. Health Phys 2016; 111: 201-208

[16] World Health Organization (WHO). lodine thyroid blocking. Guidelines for use in planning for and responding to radiological and nuclear emergencies. Geneva: World Health Organization; 2017

[17] Autorité de Sureté Nucléaire (ASN). Guide national. Intervention médicale en cas d'évènement nucléaire ou radiologique. Version $\vee 3.6$ 2008

[18] Strahlenschutzkommission (SSK). Verwendung von Jodtabletten zur Jodblockade der Schilddrüse bei einem Notfall mit Freisetzung von radioaktivem Jod Empfehlung der Strahlenschutzkommission. Verabschiedet in der 294. Sitzung der Strahlenschutzkommission am 26April 2018 https://www.ssk.de/SharedDocs/Beratungsergebnisse_ PDF/2018/2018-04-26]odmerk.pdf?__blob= publicationFile

[19] Wolff J, Chaikoff IL. Plasma inorganic iodide as a homeostatic regulator of thyroid function. J Biol Chem 1948; 174: 555-564

[20] Leung AM, Braverman LE. Consequences of excess iodine. Nat Rev Endocrinol 2014; Mar 10: 136-142

[21] Riggs DS. Quantitative aspects of iodine metabolism. Pharmacol Rev 1952; 4: $284-370$

[22] International Commission on Radiological Protection (ICRP). Dose coefficients 3279 for intakes of radionuclides by workers. ICRP Publication 68. Oxford: Pergamon Press; 1994

[23] International Commission on Radiological Protection (ICRP). Individual monitoring for internal exposure of workers. Replacement of ICRP Publication 54. ICRP Publication 78. Oxford: Pergamon Press; 1997

[24] Darrouzet E, Lindenthal S, Marcellin D et al. The sodium/iodide symporter: State of the art of its molecular characterization. Biochimica and Biophysica Acta 2014; 1838: 244-253 
[25] Chou TC, Talaly P. A simple generalized equation for the analysis of multiple inhibitions of Michaelis-Menten kinetic systems. J Biol Chem 1977; 252: 6438-6442

[26] Schäuble S, Stavrum AK, Puntervoll P et al. Effect of substrate competition in kinetic models of metabolic networks. FEBS Letters 2013; 587: 2818-2824

[27] Ramsden D, Passant FH, Peabody CO et al. Radioiodine uptakes in the thyroid studies of the blocking and subsequent recovery of the gland following the administration of stable iodine. Health Phys 1967; 13: 633-646

[28] Wootton R, Hammond B]. A computer simulation study of optimal thyroid radiation protection during investigations involving the administration of radioiodine-labelled pharmaceuticals. $\mathrm{Br}$ J Radiol 1978; 51: 265-272

[29] Blum M, Eisenbud M. Reduction of thyroid irradiation from I-131 by potassium iodide. JAMA 1967; 200: 1036-1040

[30] Marinelli L, Quimby E, Hine G. Dosage determination with radioactive isotopes: II. Practical considerations in therapy and protection. Am J Roentgenol Radium Ther Nucl Med 1948; 59: 260-280

[31] Hine G, Brownell G. Radiation Dosimetry. New York: Academic Press; 1956

[32] Stabin M. Nuclear medicine dosimetry. Phys Med Biol 2006; 51: R187-R202

[33] Spetz J. Biodistribution of free 125I, 131I and 211At in rats. Master of Science thesis. Department of Radiation Physics. University of Gothenburg; Sweden: 2010

[34] Birchall A, Puncher M, Marsh JW et al. IMBA Professional Plus: A flexible approach to internal dosimetry. Radiat Prot Dosimetry 2007; 125: 194-197

[35] Johansson L, Leide-Svegborn S, Mattsson S et al. Biokinetics of iodide in man: Refinement of current ICRP dosimetry models. Cancer Biother Radiopharm 2003; 18: 445-450

[36] Harvey RP, Hamby DM, Palmer TS. A modified ICRP 66 iodine gas uptake model and its parametric uncertainty. Health Phys 2004; 87: 490-506

[37] Matsuda N, Kumagai A, Ohtsuru A et al. Assessment of internal exposure doses in Fukushima by a whole body counter within one month after the nuclear power plant accident. Radiat Res 2013; 179: 663-668

[38] Strahlenschutzkommission (SSK). Radiation protection principles for radioiodine therapy. Recommendation by the German Commission on Radiological Protection. Adopted at the 142nd session of the Commission on Radiological Protection on 5/6 December, 1996. In Veröffentlichungen der Strahlenschutzkommission Band 40. Gustav Fischer Verlag; 1998

[39] Goldsmith SJ. Radioactive iodine therapy of differentiated thyroid carcinoma: Redesigning the Paradigm. Mol Imaging Radionucl Ther 2017; 26: (Suppl 1): 74-79

[40] Rall JE, Robbins J, Lewallen CG. The thyroid. In Pincus G, Thimann KV, Astwood EB. eds. The hormones. Physiology, chemistry, and applications. New York London: Academic Press; 1964: P 159-440

[41] McConahey WM, Keating FR Jr., Power MH. An estimation of the renal and extrarenal clearance of radioiodine in man. . Clin Invest 1951; 30: 778-780

[42] Stanley MM. The direct estimation of the rate of thyroid hormone formation in man; the effect of the iodide ion on thyroid iodine utilization. J Clin Endocrinol Metab 1949; 9: 941-954

[43] Hänscheid H, Reiners C, Goulko G et al. Facing the nuclear threat: Thyroid blocking revisited. J Clin Endocrinol Metab 2011; 96 : 3511-3516

[44] Orgiazzi J. L'iode stable et la prévention des expositions a l'iode radioactif. Energies-Santé 1996; 7: 379-385
[45] Wolff J. lodide goiter and the pharmacologic effects of excess iodide. Am J Med 1969; 47: 101-124

[46] Ericson LE, Nilsson M. Structural and functional aspects of the thyroid follicular epithelium. Toxicol Lett 1992; 64/65: 365-373

[47] Simchowitz L. Interactions of bromide, iodide, and fluoride with the pathways of chloride transport and diffusion in human neutrophils. J Gen Physiol 1988; 91: 835-860

[48] Fong P. Thyroid iodide efflux: a team effort? J Physiol 2011; 589: (Pt24) 5929-5939

[49] Hays MT. Kinetics of the human thyroid trap: Effects of iodide, thyrotropin, and propylthiouracil. J Nucl Med 1979; 20: 944-949

[50] Bazin JP, Fragu P, Di Paola R et al. Tubiana. Early kinetics of thyroid trap in normal human patients and in thyroid disease. Eur ] Nucl Med 1981; 6: 317-326

[51] Merrill EA, Clewell RA, Robinson PJ et al. PBPK model for radioactive iodide and perchlorate kinetics and perchlorate-induced inhibition of iodide uptake in humans. Toxicol Sci 2005; 83: 25-43

[52] DeGroot L], Decostre P, Phair R. A mathematical model of human iodine metabolism. J of Clin Endocrinol \& Metab 1971; 32: 757-765

[53] Matsunaga T, Kobayashi K. Sensitivity analysis on the deposition of inhaled radioactive iodine and the effectiveness of iodine prophylaxis. Jpn J Health Phys 2001; 36: 31-44

[54] Eng PH, Cardona GR, Fang SL et al. Escape from the acute Wolff-Chaikoff effect is associated with a decrease in thyroid sodium/iodide symporter messenger ribonucleic acid and protein. Endocrinology 1999; $140: 3404-3410$

[55] Chung HR. lodine and thyroid function. Ann Pediatr Endocrinol Metab 2014; 19: 8-12

[56] Bürgi H. lodine excess. Best Pract Res Clin Endocrinol Metab 2010; 24 107-115

[57] Koutras D, Livadas D. The minimum dose of potassium iodide which inhibits the thyroidal radioiodine uptake. Nucl Med 1966; 5: 256-261

[58] Sternthal E, Lipworth L, Stanley B et al. Suppression of thyroid radioiodine uptake by various doses of stable iodide. $\mathrm{N}$ Engl J Med 1980; 303: 1083-1088

[59] Plummer HS. The value of iodine in exopthalmic goiter. J lowa Med Soc 1924; 14: 66-73

[60] Okamura K, Sato K, Fujikawa M et al. Remission after potassium iodide therapy in patients with Graves hyperthyroidism exhibiting thionamide-associated side effects. J Clin Endocrinol Metab 2014; 99 : 3995-4002

[61] Calissendorff J, Falhammar H. Lugol's solution and other iodide preparations: Perspectives and research directions in Graves disease. Endocrine 2017; 58: 467-473

[62] Delange F. Administration of iodized oil during pregnancy: A summary of the published evidence. Bull WHO 1996; 74: 101-108

[63] Finkelstein R, Jacobi M. Fatal iodine poisoning: A clinico-pathologic and experimental study. Adv Intern Med 1937; 60: 1283-1296

[64] Tresch DD, Sweet DL, Keelan MHJ. Acute iodide intoxication with cardiac irritability. Arch Intern Med 1974; 134: 760-762

[65] Georgitis W], McDermott MT, Kidd GS. An iodine load from waterpurification tablets alters thyroid function in humans. Mil Med 1993; 158: 794-797

[66] Leggett R. An age-specific biokinetic model for iodine. J Radiol Prot 2017; 37: 864-882

[67] Berkovski V. New iodine models family for simulation of short-term biokinetic processes, pregnancy and lactation. Food Nutrition Bulletin. 2002; 23(3, supplement) 87-94 
[68] Sun XF, Yang XF. Developmental effects of toxic doses of iodine. In Preedy VR, Burrow GN, Watson R. eds. Comprehensive handbook of iodine: Nutritional, biochemical, pathological and therapeutic aspects. Amsterdam Boston Heidelberg London Oxford New York Paris San Diego San Francisco Singapore Sidney Tokyo: Academic Press, Elsevier; 2009: P 855-864
[69] Connelly KJ, Boston BA, Pearce EN et al. Congenital hypothyroidism caused by excess prenatal maternal iodine ingestion. J Pediatr 2012; 161: 760-762

[70] Girling JC. Thyroid disorders in pregnancy. Cur Obstetrics \& Gynaecol 2003; 13: 45-51

[71] Nauman J, Wolff J. lodide prophylaxis in Poland after the Chernobyl reactor accident: benefits and risks. Am J Med 1993; 94: 524-532 